\title{
Challenges in Diabetic Care - Implementing a New Patient Education Programme
}

\section{Avann C, Kershaw M, Drummond L, Krone R}

Birmingham Children's Hospital

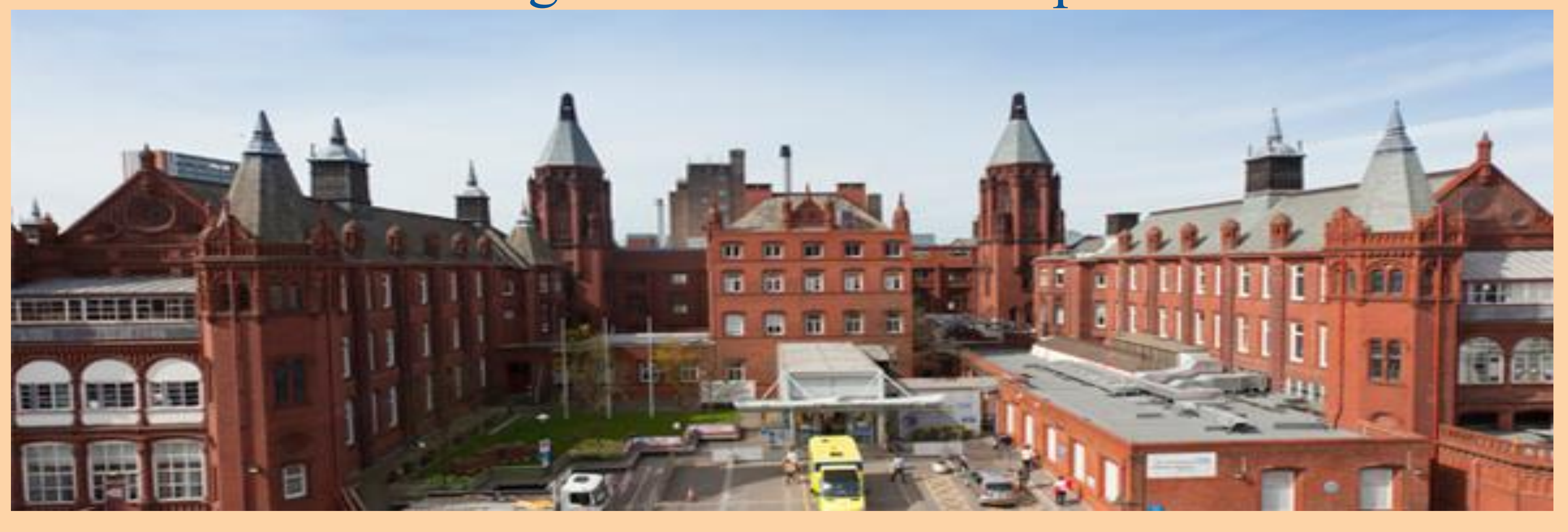

\section{Introduction}

Poor HbA1c in the first year following diagnosis of type 1 diabetes is a predictor of poor metabolic control and early development of complications. Achieving good glycaemic control requires compliant, well-educated patients.

In October 2013, we introduced a revised and extended 'Newly Diagnosed Patient Education Programme' in which a total of 20 sessions are delivered by the multidisciplinary team.

\section{BCH Programme}

20 sessions (each $45-60$ mins) providing patients with a total of 15-20 hours of structured education covering all aspects of diabetic care.

The programme starts immediately after diagnosis.

Sessions are delivered over a period of 6 weeks and by members of the MDT:

-Diabetologist (6)

-PDSN (7)

- Dietician (5)

- Social worker (3)

- Psychologist (1)

The majority of sessions are delivered within the first 2 weeks following diagnosis.

Whilst most sessions are hospital based, 5 are based around home visits, allowing the team to further gain insight into family dynamics and social background

Aim: To assess the effect of the new policy for newly diagnosed Type 1 diabetics on their HbA1c in the $1^{\text {st }}$ year.

\section{Method}

Type 1 diabetics diagnosed October 2013October 2014, who completed the new education programme were analysed and compared to a pre-intervention group diagnosed January-December 2010.

Data obtained included $\mathrm{HbA} 1 \mathrm{c}$ during the first year post diagnosis, patient demographics and psychosocial factors

\section{Results}

24 patients ( 8 males, 16 females) were included in the study group compared to 17 (6 males, 11 females) in the pre-intervention group.

\begin{tabular}{l|l|l} 
& $\begin{array}{l}\text { Study group } \\
\text { (Oct 2013 - Oct } \\
\text { 2014) }\end{array}$ & $\begin{array}{l}\text { Pre-intervention } \\
\text { group } \\
(2010)\end{array}$ \\
\hline Number & 24 & 17 \\
\hline M:F & $8: 16$ & $6: 11$ \\
\hline Mean age & $10(3.5-15 y)$ & $\begin{array}{l}8.9(1 y 10 m- \\
14 y 9 m)\end{array}$ \\
\hline DKA at diagnosis & $4(16 \%)$ & $5(29 \%)$ \\
\hline $\begin{array}{l}\text { Discharged straight } \\
\text { from ED }\end{array}$ & $15(62 \%)$ & $8(47 \%)$ \\
\hline Non DKA admitted & $5(21 \%)$ & $4(23 \%)$ \\
\hline Social Issues & $\begin{array}{l}2 \text { CAF, 9 spilt } \\
\text { families, 3 domestic } \\
\text { violence }\end{array}$ & $\begin{array}{l}3 \text { split families, } 2 \\
\text { chaotic }\end{array}$ \\
\hline $\begin{array}{l}8(2 \text { clinical } \\
\text { depression) }\end{array}$ & 2 \\
\hline Psychology F/U &
\end{tabular}

HbA1c at diagnosis was $11.4 \%$ for the study group compared to $10.2 \%$ in the pre-intervention group.

Whilst at 6-8 weeks similar $\mathrm{HbA1c}$ levels were achieved (8.1\% vs. $8.0 \%$ ), $\mathrm{HbA} 1 \mathrm{c}$ at 12 months measured $8.1 \%$ vs. $7.6 \%$, but a similar percentage of patients in both groups achieved an Hba1c < $7.5 \%$ (55\% vs. $53 \%$ ).

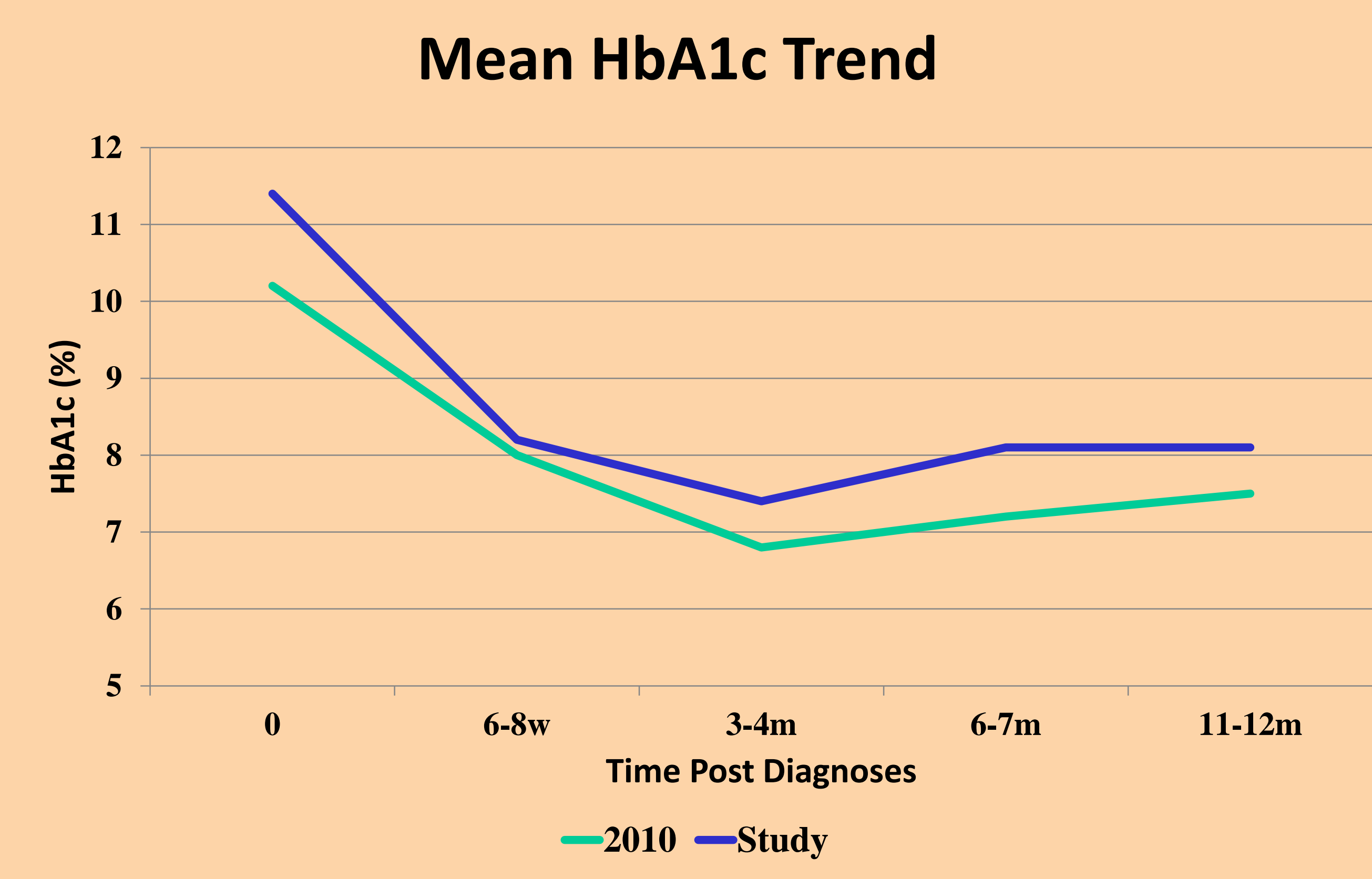

3 patients within the study group (age 11y, $13 y, 15 y)$ had significantly worse $\mathrm{HbA} 1 \mathrm{cs}$ at 1 year than the remainder of their cohort $(14 \%, 11.9 \%$ and $10.9 \%$ respectively). All have significant psychosocial issues. Excluding these 3 patients, the mean $\mathrm{HbA} 1 \mathrm{c}$ at 1 year in the study group would drop from $8.1 \%$ to $7.3 \%$, highlighting a high impact area where additional input could be targeted.

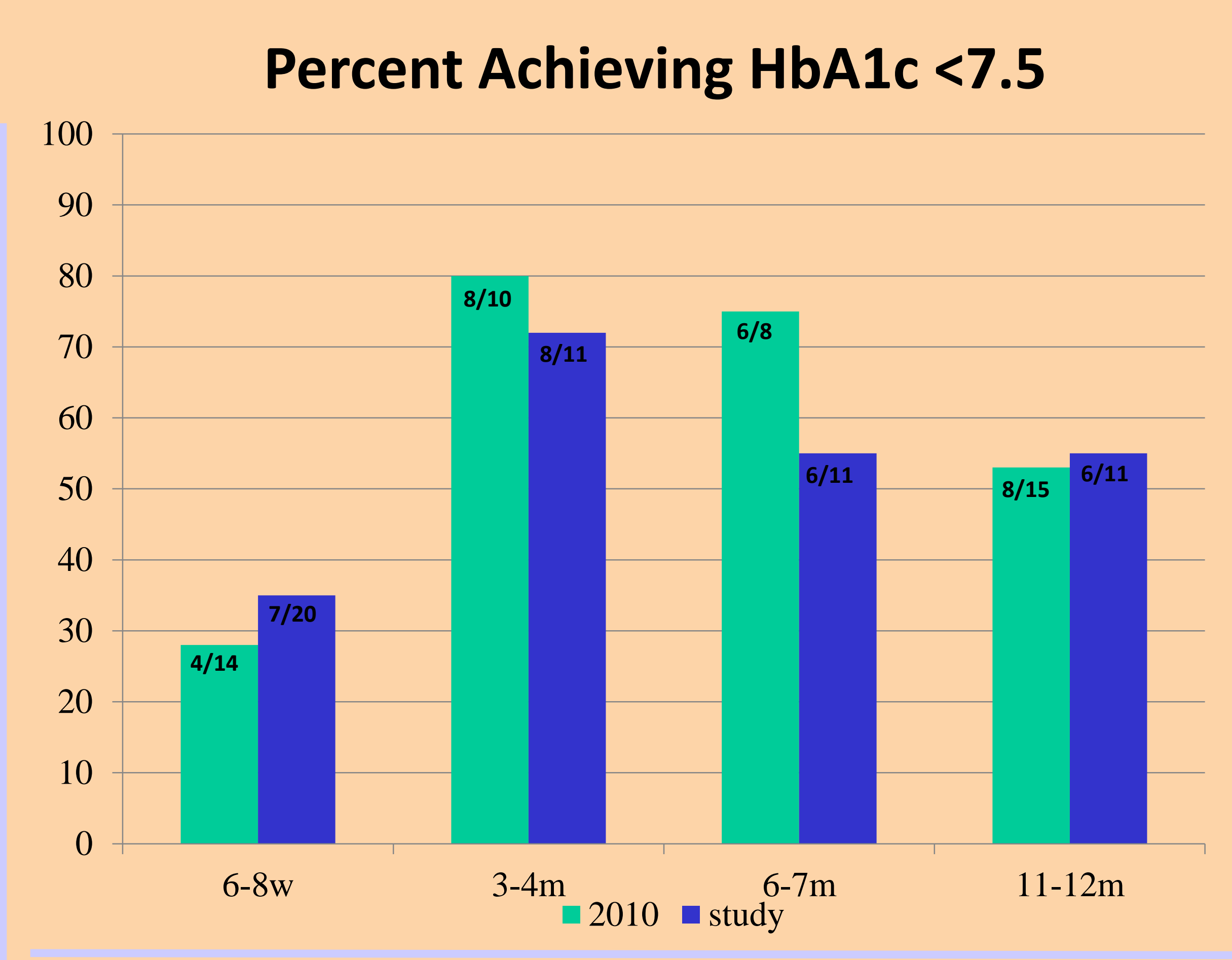

\section{Discussion}

Psychosocial factors varied greatly between groups, with the study group having higher numbers of social risk factors (CAF 2 vs. 0 , split families 9 vs. 3 , domestic violence 3 vs. 0 , ongoing psychology support 8 vs. 2 , clinical depression 2 vs. 0), impacting on diabetes management. It is encouraging that despite this, the percentage of patients achieving $\mathrm{HbA} 1 \mathrm{c}$ levels $<7.5 \%$ one year after diagnosis is similar between groups.

The $\mathrm{BCH}$ diabetic team provides care to a high proportion of patients from socially deprived backgrounds. This finding highlights barriers to successful diabetes management and has prompted us to further evaluate the social support we can provide to these high risk individuals.

Conclusion: Current data highlights that the
service is providing care to a socially
challenging population and will need further
consideration and tailoring. Long term
outcomes are awaited.

\section{References}

- BCH Guidelines for Care and Education of Children Newly Diagnosed with Type 1 diabetes

- Global IDF/ISPAD guidelines for diabetes in children and adolescents with diabetes

NICE guidelines 2004

Samuelsson et al. "A high mean -HbA1c value 3-15 months after diagnosis of type 1 diabetes in childhood is related to metabolic control, macroalbuminuria, and retinopathy in early adulthood - a pilot study using two nation-wide population based quality registries". Paediatric using two nation-wide popu

Viswanathan et al. The utility of hemoglobin A1c at diagnosis for the prediction of future glycemic control in children with type 1 diabetes. prediction of future glycemic control in chiles Res Clin Pract 2011: 92: 65-68

Diabetes Res Clin Pract 2011: 92: 65-68
Edge JA. Persistent individual tracking within overall improvement in HbA1c in a UK paediatric diabetes clinic over 15 years. Diabet Med. 2010 HbA1c in a UK paediatric diabetes clinic over 15 years. Diabet Med. 2010
Nov;27(11):1284-8.

Cengiz E. Pediatric diabetes consortium T1D New Onset (NeOn) study: clinical outcomes during the first year following diagnosis. Pediatr Diabetes. 2014 Jun;15(4):287-93.

- Rewers et al. Assessment and monitoring of glycemic control in children and adolescents with diabetes. Pediatric Diabetes 2007;8: 408-418. 